\title{
STUDIES OF THE SEISMIC AND CRUSTAL DEFORMATION PATTERNS OF AN ACTIVE FAULT: PINON FLAT OBSERVATORY
}

\author{
Johnathan Berger and James N. Brune \\ University of California \\ IGPP, A-025 \\ La Jolla, California 92093
}

USGS CONTRACT NO. 14-08-0001-18398

Supported by the EARTHQUAKE HAZARDS REDUCTION PROGRAM

OPEN-FILE NO. $\quad 81-879$

U.S. Geological Survey

OPEN FILE REPORT

This report was prepared under contract to the U.S. Geological Survey and has not been reviewed for conformity with USGS editorial standards and stratigraphic nomenclature. Opinions and conclusions expressed herein do not necessarily represent those of the USGS. Any use of trade names is for descriptive purposes only and does not imply endorsement by the USGS. 


\section{Final Technical Report}

Studies of the Seismic and Crustal Deformation Patterns of an Active Fault: Piñon Flat Observatory

$$
14-08-0001-18398
$$

Frank Wyatt

Jonathan Berger \& James N. Brune, Principal Investigators

A collection of nearly twenty instruments is being operated at Piñon Flat Observatory (PFO) in an effort to monitor the ambient strain, tilt, and gravity near an active fault zone. Secondary to this function, the goal of the research program at PFO is to determine the factors limiting the accuracy of observatory-based geophysical instrumentation. Because the signals of interest occur at such low frequencies (e.g., one cycle per year) the process of identifying these factors is not a simple one. Subsequent to performing an experiment, it is often necessary to collect many months of data in order to quantify the results. The array of instruments at PFO provides a data base that is used to accelerate the process.

A comparison of the recent records from the short fluid tiltmeter $(50 \mathrm{~m})$ and the Northwest-Southeast strainmeter $(731 \mathrm{~m})$ at PFO illustrates the value of simultaneous measurements. Figure 1 presents the tiltmeter observations for the period 1979.64 to 1981.04 . Also shown are the instrument fluid temperature, which is in equilibrium with the ground temperature at a depth of $.5 \mathrm{~m}$, and the daily precipitation. A feature of this record that stands out is the symmetric cusp in the tilt around the time of a local $\left(M_{L} 5.3\right)$ earthquake. The observed tilt offset at the time of the event, $.112 \mu$ radians, is in excellent agreement with the 
value determined by a simple calculation for the deformation related to the faulting (.106 $\mu$ radians). However, the factors responsible for the cusp are not as clear. We believe that both the upward and downward changes in trend were caused by displacements in the materials under the instrument in response to the rainfalls that occurred in the preceding weeks.

The evidence for this conclusion, is provided by examining Figure 2. This figure displays the uncorrected strain observations and the data corrected for monument displacement at the North-West end (only). These are presented on a time and magnitude scale equal to that of Figure 1. The size of the tidal signals (indicated by the width of the traces) suggests that the vertical scales are different. However, a tiltmeter responds both to accelerations and deformation, which results in the tidal signals being roughly three times greater than the purely deformational signals recorded by a strainmeter. There is no indication of unusual deformation associated with the local earthquake (1980.1 to 1980.2) in the strain records. Indeed, we have evidence that the conspicuous changes in the other portions of the strain record are due to displacements of the South-East reference monument. In particular, the change which occurred near the start of 1980 was due to recementing the South-East monument.

Based on these observations, it is clear that additional instrument improvement is possible. The tiltmeter baselength has recently been extended to $535 \mathrm{~m}$, with vertical strainmeters at each end to monitor the undesirable motions of the near surface monuments. Similarly the strainmeter is to be improved by installing a second "optical anchor" at the southeast end of the instrument. We anticipate that these changes will result in reducing the variance of the low frequency observations significantly. 


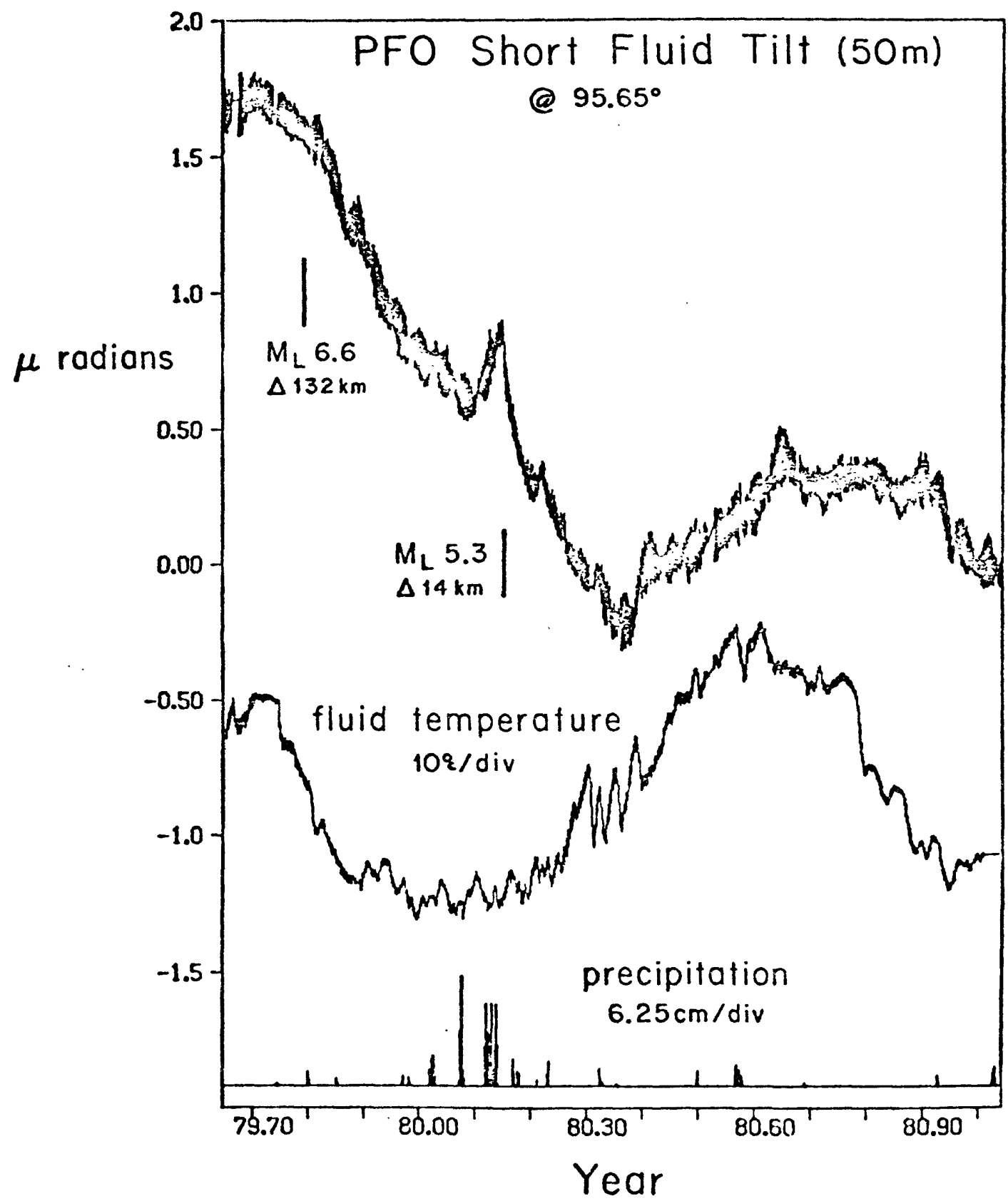

Figure 1. 


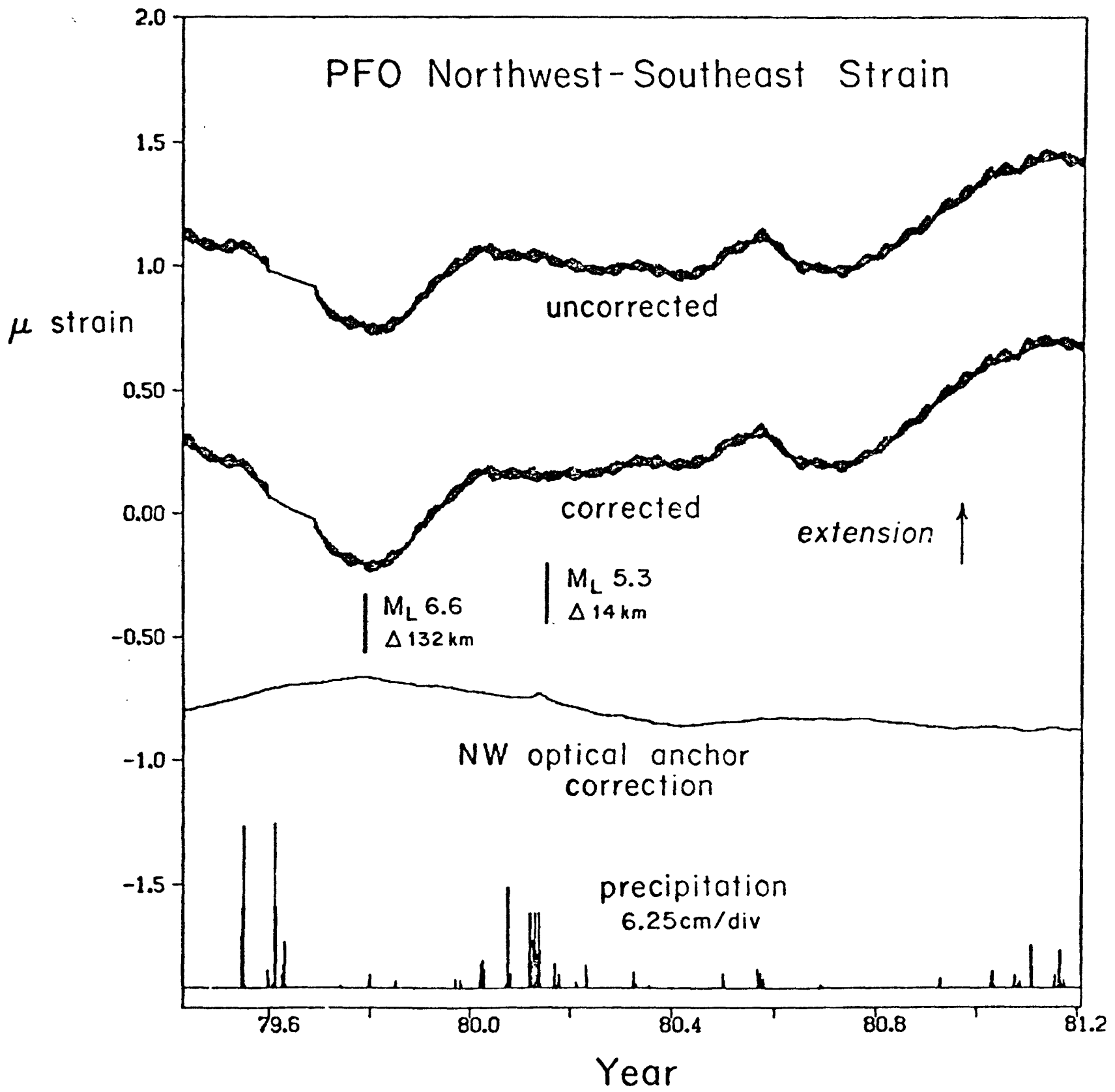

Figure 2. 